\title{
Intestinal helminth co-infection and associated factors among tuberculosis patients in Arba Minch, Ethiopia
}

\author{
Getaneh Alemu* and Mohammedaman Mama
}

\begin{abstract}
Background: Helminths affect the outcome of tuberculosis by shifting cell mediated immune response to humoral and by total suppression of the host immune system. On the reverse, Mycobacterium infection favors immune escape of helminths. Therefore assessing helminth co-infection rate and predisposing factors in tuberculosis patients is mandatory to set strategies for better case management.

Methods: Facility based cross-sectional study was conducted in Arba Minch to assess the prevalence and associated factors of intestinal helminths among pulmonary tuberculosis patients from January to August, 2016. A structured questionnaire was used to capture data about socio-demographic characteristics, clinical history and possible risk factors for intestinal helminth infections. Height and weight were measured to calculate body-mass index. Appropriate amount of stool was collected and processed by direct saline and formol-ether concentration techniques following standard protocols. All the data were analyzed using SPSS version 20.0.

Results: A total of 213 (57.3\% male and 42.7\% female) pulmonary tuberculosis patients were participated in the study. The overall co-infection rate of intestinal parasites was $26.3 \%$. The infection rate of intestinal helminths account $24.4 \%$ and that of intestinal protozoa was 6.1\%. Ascaris lumbricoides accounted the highest frequency of 11.3\%. Living in rural residence $(A O R=3.175,95 \% \mathrm{Cl}: 1.102-9.153, p=0.032)$, Eating vegetables/ fruits without washing or peeling off $(\mathrm{AOR}=2.208,95 \% \mathrm{Cl}: 1.030-4.733, p=0.042)$ and having body-mass index <18.5 (AOR=3.511, 95\% Cl: 1.646-7.489, $p=0.001$ ) were associated with intestinal helminth infection.

Conclusion: The infection rate by intestinal helminths was $24.4 \%$. Ascaris lumbricoides was the most prevalent helminth. Residence, habit of washing vegetables/fruits before use and body-mass index were associated factors with intestinal helminthiasis. Therefore health care providers should screen and treat TB patients for intestinal helminthiasis in order to ensure good prognosis.
\end{abstract}

Keywords: Helminth, Tuberculosis, Co-infection

\section{Background}

Tuberculosis (TB) remains one of the world's major public health problems $[1,2]$. Even if TB is slowly declining each year since 2000, death from the disease is still unacceptably high [1]. According to World Health Organization (WHO) report, about 10.4 million people developed TB and 1.4 million died from all forms of TB in 2015 globally. One quarter of the cases were in the African Region. Ethiopia is ranked $8^{\text {th }}$ and $2^{\text {nd }}$ among

\footnotetext{
* Correspondence: getanehmlt@gmail.com

Department of Medical Laboratory Science, Arba Minch University, Arba Minch, Ethiopia
}

(c) The Author(s). 2017 Open Access This article is distributed under the terms of the Creative Commons Attribution 4.0 International License (http://creativecommons.org/licenses/by/4.0/), which permits unrestricted use, distribution, and reproduction in any medium, provided you give appropriate credit to the original author(s) and the source, provide a link to the Creative Commons license, and indicate if changes were made. The Creative Commons Public Domain Dedication waiver (http://creativecommons.org/publicdomain/zero/1.0/) applies to the data made available in this article, unless otherwise stated. respectively. The incidence and mortality (excluding HIV related deaths) because of all forms of TB were 192 and 26/100,000 population, respectively in 2015. It remains one of the leading causes of mortality due to communicable diseases in Ethiopia [1].

Control of Mycobacterium tuberculosis (M. tuberculosis) infection is mainly dependent on the success of the interaction between innate and adaptive immune responses of the host. The cell mediated immunity mainly determines the disease outcome [3, 4]. In most immuno-competent 
individuals, infected macrophages interact with both CD4+ and $\mathrm{CD} 8+\mathrm{T}$ cells and control the infection mainly via $\mathrm{T}$ helper(Th) -1 type inflammatory response $[4,5]$. Individuals whose immunity is suppressed or shifted toTh2 type are more susceptible to develop active infection and more acute morbidity. Malnutrition, diabetes mellitus, HIV, helminth infection, different forms of cancer and prolonged use of steroid drugs are among the factors which suppress/shift the immune response [4-6]. Helminths induce a strong Th2-type immune response characterized by production of cytokines like interleukin (IL) - 4, IL-5, IL-9, and IL-13 and increased levels of circulating IgE antibodies and eosinophils [4]. Prolonged Th2 response is followed by activation and expansion of both natural and inducible regulatory $\mathrm{T}$ cells $[6,7]$. All these immune-modulations favor survival, multiplication and dissemination of $M$. tuberculosis to develop active TB and the associated sequelae $[8,9]$. Such independent immune-modulation by both helminths and M. tuberculosis determines the pathogenesis and outcome of both infections [10].

The geographical distribution of intestinal helminth infections and TB overlap substantially that co-infection in humans has been a major emerging public health problem in poorest regions of the world $[3,4,11]$. Strong association between active pulmonary TB (PTB) and helminthiasis has been shown from previous studies $[3,11,12]$. However the helminth species and rate of coinfection with PTB vary from place to place. Climate conditions, socio-demographic characteristics and living standards of the population are believed to determine the type of helminths existing in various $\mathrm{TB}$ endemic areas. This necessitates sufficient data to be collected about the co-infection rate and common co-infecting helminth species at different geographical settings; because the data will be an input for policy makers to modify TB case management protocols at local level based on the existing conditions. However very limited data is available in Ethiopia that is generated only from Gondar, Northwest Ethiopia [2-4, 13]. As to the best of our knowledge, no similar study has been conducted in southern Ethiopia so far.

On the other hand, the clinical significance and associated risk factors of helminths is more related to, and extensively studied in children. This is because of considering asymptomatic or sub-clinical level of morbidity in adults. However in adults with concurrent chronic diseases, helminthes behave aggressively to result in severe morbidity and even death [2]. Despite this, data about the infection rate and associated risk factors among adults is lacking in the study area. Therefore in this study, we have assessed intestinal helminth coinfection rate and associated factors among PTB patients in Southwest Ethiopia.

\section{Methods}

\section{Study design and area}

Facility based cross-sectional study was conducted in selected TB clinics of Arba Minch town and Arba Minch zuria district from January to August, 2016. Arba Minch is located $454 \mathrm{kms}$ south of Addis Ababa. It is found at an altitude of 1200-1300 m above sea level with an average annual temperature of $29.7{ }^{\circ} \mathrm{C}$ and rain fall of $900 \mathrm{~mm}$ [14]. In the town, there is one hospital and two health centers. All the three institutions have TB diagnosis laboratories and treatment clinics. Arba Minch zuria woreda is situated at average of $1285 \mathrm{~m}$ above sea level surrounding Arba Minch town [14]. There are seven health centers in the woreda giving routine health services including TB diagnosis and treatment.

\section{Selection of study participants}

Information about PTB patient flow at each governmental health institutions of Arba Minch town and surrounding rural district was collected first. Relatively, Arba Minch Hospital, two health centers in the town (Arba Minch health center and Shecha health center) and one health center in Arba Minch zuria district (Shelle health center) were found to be with high PTB patient flow. Therefore, TB clinics in the above mentioned health facilities were purposively selected for data collection. Consecutive newly diagnosed and on treatment PTB patients who attended TB clinics during the study period and have given informed written consent were included in the study. Only PTB patients diagnosed based on the national diagnosis guideline and 1565 years of age were recruited. Cases are diagnosed to be PTB patients if there is persistent (for $\geq 2$ weeks) cough two sputum examinations reveal positive result for acid fast bacilli or one sputum examination is positive and chest $\mathrm{x}$-ray result is suggestive for PTB.

Pregnant mothers, patients who have taken antihelminth drug within three months before data collection and severely ill patients who are unable to respond to research questions were excluded from the study. Patients with other immunosuppressive chronic diseases were excluded by referring to their medical records. Under 15 age groups were also excluded aiming to assess intestinal helminth prevalence and associated factors among adolescents and adults. Patients above 65 years of age were not involved in the study as their immune response is expected to be weakened naturally.

\section{Data collection}

\section{Socio-demographic characteristics}

Nurses who are fluent speakers in the local language (Gamo) were trained for data collection. A pretested structured questionnaire administered through face to face interview was used to collect data about socio- 
demographic characteristics and associated factors for intestinal helminth infection after translating to the local language. Clinical data was also collected by interview and from the patients' log book.

\section{Anthropometric measures}

Body-mass index (BMI) is considered as the most suitable, objective anthropometric indicator of nutritional status of adults. To calculate BMI, measurements of height and weight were under taken by trained nurses following a standard procedure explained elsewhere [15]. According to the $\mathrm{WHO}$ definition, individuals with $\mathrm{BMI}<18.5$ are malnourished and those with $\mathrm{BMI}<16$ are severely malnourished [16].

\section{Laboratory methods}

An appropriate amount of stool sample was collected and delivered to Parasitology laboratories of Arba Minch hospital or Arba Minch University, college of medicine and health sciences teaching laboratory following standard collection and transportation protocols [17]. About $50 \mathrm{mg}$ of stool was processed immediately after collection using direct saline method in order to identify motile trophozoites of intestinal protozoa and larvae of $S$. stercoralis. One or two drops of normal saline were mixed with an approximate of $50 \mathrm{mg}$ stool on a clean slide. A uniform suspension was made using an applicator stick and covered with a clean cover slip. The entire preparation was systematically screened using the $10 \times$ and $40 \times$ objective lenses for detection of protozoa trophozoites and cysts as well as helminth ova and larvae. The remaining stool was processed by the formol-ether concentration technique, which is considered as the most sensitive for most intestinal helminths and protozoan cysts. About $1 \mathrm{gm}$ of stool was added to a clean $15 \mathrm{ml}$ conical test tube containing $7 \mathrm{ml}$ of $10 \%$ formal saline. The stool was gently suspended with the formal saline using applicator stick. The suspension was filtered through a sieve in to a second centrifuge tube. After adding $3 \mathrm{ml}$ of diethyl ether, contents in the second tube were centrifuged at medium speed $(2500 \mathrm{rpm})$ for $5 \mathrm{~min}$. The supernatant was poured off and smear on a clean slide was prepared from the sediment and covered with clean cover slip. The preparation was examined in the same way as that of the direct saline method. Negative results were reported after assessing the whole smear under $10 \mathrm{x}$ objective. Investigators supervised all aspects of data collection and laboratory procedures.

\section{Statistical analysis}

Data was edited, cleaned, entered and analysed using SPSS version 20.0. Descriptive statistics are calculated to describe the study population characteristics. Bivariate logistic regression is used to assess associations between categorical variables. Multivariate regression model then followed for variables with $p \leq 0.25$ in the bivariate analysis. Association between variables was considered statistically significant only if $P$-value $<0.05$ at $95 \%$ confidence level.

\section{Results}

\section{Socio-demographic and clinical data}

A total of 213 PTB patients participated in the study. Eighty six of them were from Arba Minch hospital while 69, 22 and 36 participants were recruited from Arba Minch, shecha and shellehealth centres respectively. One hundred twenty-two (57.3\%) were male and 91 (42.7\%) were female participants. The highest number of participants, 136 (31\%), belong to the age group 15-34 years old while the lowest number, 7 (3.3\%), belongs to $\geq 55$ years of age. Majority (92.0\%) of the study participants commonly cook their food at home. Among those having frequent habit of eating raw vegetables/fruits, 136 (66.3\%) wash or peel off before use. Most respondents, 204 (95.8\%) and 210 (98.6\%), often wash hands before meal and defecation respectively (Table 1).

Out of 213 participants, 24 (11.3\%) had self-reported diarrhea within the last 3 months before this data was collected. Ten of them contracted the last diarrheal episode within the last two weeks. Two hundred nine (98.1\%) were tested for HIV of whom 20 (9.6\%) were positive. About one third (33.3\%) were with BMI $<18.5$. During the time of interview, 200 (93.9\%) of the participants have already started anti-TB treatment while the rest $13(6.1 \%)$ were contacted as soon as diagnosed before the start of treatment (Table 2).

\section{Prevalence of parasites}

The overall co-infection rate of intestinal parasites was $26.3 \%$. The prevalence of intestinal helminths account $24.4 \%$ and that of intestinal protozoans was $6.1 \%$. Totally six helminths were detected among which Ascaris lumbricoides (A. lumbricoides) was with the highest frequency $(24,11.3 \%)$ followed by hook worms $(18,8.5 \%)$. Giardia lamblia (G. lamblia) and Entamoeba histolytica (E. histolytica) were the only intestinal protozoans detected from $10(4.7 \%)$ and $4(1.9 \%)$ participants respectively (Table 3).

\section{Factors associated with intestinal helminth co-infection}

Residence had significant association with intestinal helminth infection $(p=0.032)$ that rural residents were 3 times more likely (AOR $=3.175,95 \%$ CI: $1.102-9.153$ ) to be infected than urban dwellers. According to the bivariate analysis model, respondents who commonly cook their food at home were 3 times more affected (95\% CI: $1.119-8.429, p=0.029)$ than those who commonly get their food from hotel; but in the multi-variate analysis, 
Table 1 Socio-demographic characteristics of TB patients attending selected health institutions of Arba Minch town and Arba Minch zuria district from January to August, 2016

\begin{tabular}{|c|c|c|c|c|}
\hline \multirow[t]{2}{*}{ Variables } & & \multicolumn{3}{|l|}{ Frequency } \\
\hline & & Number (n) & Percent (\%) & Total no. of respondents \\
\hline \multirow[t]{2}{*}{ Sex } & Male & 122 & 57.3 & 213 \\
\hline & Female & 91 & 42.7 & \\
\hline \multirow[t]{3}{*}{ Age group } & $15-34$ & 136 & 63.8 & 213 \\
\hline & $35-54$ & 70 & 32.9 & \\
\hline & $55-65$ & 7 & 3.3 & \\
\hline \multirow[t]{2}{*}{ Marital status } & Single & 115 & 54 & 213 \\
\hline & Married & 98 & 46 & \\
\hline \multirow[t]{2}{*}{ Educational level } & Illiterate & 60 & 28.2 & 213 \\
\hline & Primary and above & 153 & 71.8 & \\
\hline \multirow[t]{2}{*}{ Residence } & Urban & 166 & 77.9 & 213 \\
\hline & Rural & 47 & 22.1 & \\
\hline \multirow[t]{2}{*}{ Have/use latrine } & Yes & 182 & 85.4 & 213 \\
\hline & No & 31 & 14.6 & \\
\hline \multirow[t]{2}{*}{$<14$ children live in the house } & Yes & 64 & 30 & 213 \\
\hline & No & 149 & 70 & \\
\hline \multirow[t]{2}{*}{ Common food source } & Cooked at home & 196 & 92.0 & 213 \\
\hline & Hotel & 17 & 8.0 & \\
\hline \multirow[t]{2}{*}{ Wash raw vegetables/fruits before use } & Often or always & 136 & 66.3 & 205 \\
\hline & Never or occasionally & 69 & 33.7 & \\
\hline \multirow[t]{2}{*}{ Habit of eating raw meat } & Often or always & 176 & 82.6 & 213 \\
\hline & Never or occasionally & 37 & 17.4 & \\
\hline \multirow[t]{2}{*}{ Hand washing habit before meal } & Often or always & 204 & 95.8 & 213 \\
\hline & Never or occasionally & 9 & 4.2 & \\
\hline \multirow[t]{2}{*}{ Hand washing habit after defecation } & Often or always & 210 & 98.6 & 213 \\
\hline & Never or occasionally & 3 & 1.4 & \\
\hline \multirow[t]{2}{*}{ Water source for washing utensils } & Pipe & 171 & 80.3 & 213 \\
\hline & River/lake/stream & 42 & 19.7 & \\
\hline \multirow[t]{2}{*}{ Water source for bathing } & Pipe & 166 & 77.9 & 213 \\
\hline & River/lake/stream & 47 & 22.1 & \\
\hline \multirow[t]{2}{*}{ Water source for drinking } & Pipe & 199 & 93.4 & 213 \\
\hline & River/lake/stream & 14 & 6.5 & \\
\hline \multirow[t]{2}{*}{ Swimming habit } & Yes & 37 & 17.5 & 212 \\
\hline & No & 175 & 82.5 & \\
\hline \multirow[t]{2}{*}{ Shoe wearing habit } & Yes & 202 & 94.8 & 213 \\
\hline & No & 11 & 5.2 & \\
\hline \multirow[t]{2}{*}{ Raise cattle } & Yes & 63 & 29.6 & 213 \\
\hline & No & 150 & 70.4 & \\
\hline \multirow[t]{2}{*}{ Raise pets (cat/dog) } & Yes & 73 & 34.3 & 213 \\
\hline & No & 140 & 65.7 & \\
\hline \multirow[t]{2}{*}{ Use night soil for farming } & Yes & 32 & 15.0 & 213 \\
\hline & No & 181 & 85.0 & \\
\hline
\end{tabular}


Table 2 Clinical history of TB patients attending selected health institutions of Arba Minch town and Arba Minch zuria district from January to August, 2016

\begin{tabular}{|c|c|c|c|c|}
\hline \multirow[t]{2}{*}{ Variables } & & \multicolumn{3}{|l|}{ Frequency } \\
\hline & & Number (n) & Percent (\%) & Total no. of respondents \\
\hline \multirow[t]{2}{*}{ History of diarrheal within 3 months } & Yes & 24 & 11.3 & 213 \\
\hline & No & 189 & 88.7 & \\
\hline \multirow[t]{3}{*}{ Time of last diarrhoea occurrence } & Before a month & 11 & & 24 \\
\hline & Before 2 weeks & 3 & & \\
\hline & Within 2 weeks & 10 & & \\
\hline \multirow[t]{3}{*}{ Duration of last diarrhoea occurrence } & > a month & 2 & & 24 \\
\hline & $<$ a month & 13 & & \\
\hline & < a week & 9 & & \\
\hline \multirow[t]{2}{*}{ Other GIT discomfort within 3 months } & Yes & 40 & 18.8 & 213 \\
\hline & No & 173 & 81.2 & \\
\hline \multirow[t]{2}{*}{ Started anti-TB treatment } & Yes & 200 & 93.9 & 213 \\
\hline & No & 13 & 6.1 & \\
\hline \multirow[t]{2}{*}{ Course of treatment } & First & 190 & 95.0 & 200 \\
\hline & Re-treatment & 10 & 5.0 & \\
\hline \multirow[t]{3}{*}{ Duration of treatment in months } & $<2$ & 45 & 22.5 & 200 \\
\hline & $2-4$ & 55 & 27.5 & \\
\hline & $>4$ & 100 & 50.0 & \\
\hline \multirow[t]{2}{*}{ Started anti-TB treatment } & Yes & 200 & 93.9 & 213 \\
\hline & No & 13 & 6.9 & \\
\hline \multirow[t]{2}{*}{ HIV status } & Positive & 20 & 9.6 & 209 \\
\hline & Negative & 189 & 90.4 & \\
\hline \multirow[t]{2}{*}{ BMI } & $<18.5$ & 71 & 33.3 & 213 \\
\hline & $\geq 18.5$ & 142 & 66.7 & \\
\hline
\end{tabular}

food source was not associated with intestinal helminthiasis. Eating vegetables/ fruits without washing or peeling off was also significantly associated with helminthiasis $(p=0.042)$. The odds of infection were 2 times higher $(\mathrm{AOR}=2.208,95 \% \mathrm{CI}$ : $1.030-4.733)$ for those eating vegetables/ fruits without washing or peeling off as compared to participants who wash or peel off before eating fruits/vegetables. Participants who often walk bare foot were at higher risk to helminth infection $(\mathrm{COR}=2.27,95 \% \mathrm{CI}$ : $1.168-4.413, p=0.016$ ) but this association was not significant when adjusted for confounding factors. Nutritional status had significant association with intestinal helminthiasis $(p=0.001)$ that participants with BMI $<18.5$ were 3.5 times at higher risk ( $\mathrm{AOR}=3.511,95 \% \mathrm{CI}: 1.646-7.489)$ of acquiring helminth infection as compared to those with $\geq 18.5$. The other considered socio-demographic and clinical factors didn't show significant level of association with intestinal helminth infection (Tables 4 and 5).

\section{Discussion}

The co-infection rate of intestinal parasites among PTB patients in this study was $26.3 \%$ (95\% CI: 20.2-32.4); higher than co-infection rate of $7.3 \%$ in China [11]. Variations in socio demographic characteristics and level of awareness about intestinal parasite transmission and prevention might be important determinants for low parasite prevalence in China as compared to the present study. Our findings show lower intestinal parasite prevalence as compared to cross-sectional study results from Gondar, Northwest Ethiopia by Alemayehu et al. (33.3\%) [13] and Afework et al. (40.5\%) [2]. Alemayehu et al. [13] conducted the study only among newly diagnosed PTB patients before starting treatment. Hence study population difference may be one factor for differences in intestinal parasite co-infection rate. Currently school based deworming for STH and schistosomiasis is being practiced bi-annually throughout Ethiopia which might also decrease the current transmission and prevalence of helminths.

In the present study, the total intestinal helminth coinfection rate at least with one helminth was $24.4 \%$ (95\%CI: 18.8-30.5). This goes in line with findings from Brazil (27.5\%) [12] and Northwest Ethiopia (29\%) [4]. Lower intestinal helminth co-infection rate (7\%) was 
Table 3 Prevalence of intestinal parasites in TB patients attending selected health institutions of Arba Minch town and Arba Minch zuria district from January to August, 2016

\begin{tabular}{lllc}
\hline Parasites & & \multicolumn{2}{l}{ Frequency } \\
\cline { 3 - 4 } & & Number (n) & Percent (\%) \\
\hline Helminths & A. lumbricoides & 24 & 11.3 \\
& Hook worm & 18 & 8.5 \\
& T. trichiura & 9 & 4.2 \\
& Taenia species & 5 & 2.3 \\
& H. nana & 2 & 0.9 \\
Number of helminth & S. stercoralis & 2 & 0.9 \\
species per participant & 2 & 40 & 18.8 \\
Protozoa & G. lamblia & 10 & 4.7 \\
& E. histolytica & 4 & 4.7 \\
Total prevalence & Helminths & 52 & 1.9 \\
& Protozoa & 13 & 24.4 \\
& Parasite & 56 & 6.1 \\
& (helminth + protozoa) & & 26.3 \\
& &
\end{tabular}

reported from China [11]. Elias et al. (71\%) [3] and Eba et al. (36.8\%) [18], both fromNorthwest Ethiopia, have reported higher infection rate of helminthes than that of the present study. The laboratory protocol followed and differences in sample size may justify for those differences. In both previous studies, 3 stool samples were collected and examined from each participant before ruling out intestinal helminthiasis. However, in the present study, we have collected and examined a single stool specimen for the sake of logistic problems. Our sample size was 213 which is much smaller than that of Eba et al. (424) [18]. The other possible reasons for helminth co-infection rate might be due to the health extension program. More than 30 thousand rural health extension workers were trained and currently have been working at community level all over Ethiopia aiming to implement preventive health packages [19]. Creating awareness about latrine construction and utilization as well as keeping personal and environmental hygiene among the community is one of the priority concerns of the program. This substantially decreases prevalence of intestinal helminths.

Ascaris lumbricoides is the most prevalent helminth in Ethiopia with one third of the population being infected $[20,21]$. Our findings support the existing literature that A. lumbricoides causes the highest co-infection rate of $11.3 \%$ among PTB patients followed by hook worms (8.5\%) and T. trichiura (4.2\%). Previous cross-sectional surveys in Ethiopia also show similar findings [3, 4, 18]. The proportion of helminth species prevalent among PTB patients varies according to a few other studies. $S$. stercoralis (72.7\%) was with the highest prevalence in a survey from Brazil [12]. Hook worms were the most frequent helminths in China and Northwest Ethiopia with rates of $4.3 \%$ and $11.1 \%$ respectively [11, 13]. A stool survey from adult outpatient attendants in Kenya also revealed highest prevalence of hook worms $(13.1 \%)$ among intestinal helminthes [22]. Variation in the relative distribution of helminth species based on environmental factors might be a reason for such differences. In rural areas where majority of people walk bare foot, hook worms may be more prevalent than A. lumbricoides. Xin et al. [23] and Alemayehu et al. [13] reported walking bare foot is associated with helminth infection. May be because most respondents are urban residents, shoe wearing habit was not associated factor in the present study.

In the present study we have shown factors associated with intestinal helminthiasis among PTB patients. The findings can help to estimate to the general adolescent/ adult population of the study area as TB patients are part of the population. Xin et al. from China reported that females are 2.05 times $(95 \% \mathrm{CI}=1.01-4.17)$ more likely to acquire intestinal parasite infections than males [23]. Females were also at higher risk according to findings in Kenya by Anderek et al. [22]. Age and sex were not significantly associated with intestinal helminth infection in this study. This finding is in line with studies conducted in China and Ethiopia [11, 13]. Variable occupational exposure status at different social settings might bring differences in exposure rate by sex.

The multivariate regression model in the present study revealed that rural residence, frequent eating of raw vegetables /fruits without washing or peeling off and BMI $<18.5$ are risk factors for helminth infection in PTB patients. Rural residents were 3.175 times more at risk than urban residents. Alemayehu et al. also reported similar finding [13]. The rural community is less likely to adopt life style changes that would reduce infection risk. Infective helminth ova are ingested with contaminated food or water to initiate infection that individuals often feeding on raw vegetables/fruits without washing or peeling off are more likely to be infected.

Nutrition screening, assessment and management are integral components of $\mathrm{TB}$ treatment and care. Therefore WHO recommended that patients with TB should be nutritionally assessed and receive nutritional care and support [24]. In this study, $33.3 \%$ of the participants were malnourished among which $35.2 \%$ were coinfected with intestinal helminths. Dodor reported 51\% prevalence of malnutrition among PTB patients prior to treatment in Ghana [25]. Similarly Anurag et al. reported that $80 \%$ of women and $67 \%$ of men TB patients had moderate to severe under-nutrition of which $52 \%$ had stunting indicating chronic under-nutrition [26]. Both patient groups who started anti-TB drug or not were 
Table 4 Factors associated with intestinal helminth co-infection among TB patients attending selected health institutions of Arba Minch town and Arba Minch zuria district from January to August, 2016

\begin{tabular}{|c|c|c|c|c|c|c|}
\hline Variable & Number examined & Rate of helminth infection (\%) & Crude OR $(95 \% \mathrm{Cl})$ & $P$ value & Adjusted OR & $P$ value \\
\hline \multicolumn{7}{|l|}{ Sex } \\
\hline Male & 122 & $32(2.6 \%)$ & $1.085(0.578-2.037)$ & 0.800 & & \\
\hline Female & 91 & $24(2.6 \%)$ & & & & \\
\hline \multicolumn{7}{|l|}{ Age } \\
\hline $15-34$ & 136 & $32(23.5 \%)$ & & 0.700 & & \\
\hline $35-54$ & 70 & $19(27.1 \%)$ & $0.826(0.427-1.527)$ & & & \\
\hline $55-65$ & 7 & $1(14.3 \%)$ & $1.846(0.214-15.909)$ & & & \\
\hline \multicolumn{7}{|l|}{ Educational status } \\
\hline Illiterate & 60 & $13(21.7 \%)$ & $1.416(0.684-2.633)$ & 0.349 & & \\
\hline Primary/above & 153 & $43(28.1 \%)$ & & & & \\
\hline \multicolumn{7}{|l|}{ Marital status } \\
\hline Single & 115 & $29(25.2 \%)$ & $1.116(0.597-2.088)$ & 0.731 & & \\
\hline Married & 98 & $27(27.6 \%)$ & & & & \\
\hline \multicolumn{7}{|l|}{ Residence } \\
\hline Urban & 166 & $46(27.7 \%)$ & $2.619(1.042-6.584)$ & 0.041 & 3.175 (1.102-9.153) & 0.032 \\
\hline Rural & 47 & $6(12.8 \%)$ & & & & \\
\hline \multicolumn{7}{|l|}{ Have/use latrine } \\
\hline Yes & 182 & $41(22.5 \%)$ & $0.529(0.234-1.193)$ & 0.125 & & \\
\hline No & 31 & $11(35.5 \%)$ & & & & \\
\hline \multicolumn{7}{|l|}{ Common food source } \\
\hline Cooked at home & 196 & $44(22.4 \%)$ & $3.071(1.119-8.429)$ & 0.029 & $2.866(0.900-9.131)$ & 0.075 \\
\hline Hotel & 17 & $8(47.1 \%)$ & & & & \\
\hline \multicolumn{7}{|c|}{ Habit of washing vegetables/fruits } \\
\hline Yes & 141 & $26(18.4 \%)$ & $2.835(1.468-5.476)$ & 0.002 & $2.208(1.030-4.733)$ & 0.042 \\
\hline No & 64 & $25(39.1 \%)$ & & & & \\
\hline \multicolumn{7}{|l|}{ Habit of eating raw meat } \\
\hline Often or always & 176 & $43(24.4 \%)$ & $0.994(0.435-2.271)$ & 0.989 & & \\
\hline Never or occasionally & 37 & $9(24.3 \%)$ & & & & \\
\hline \multicolumn{7}{|c|}{ Hand washing habit before meal } \\
\hline Often or always & 204 & $48(23.5 \%)$ & $0.385(0.099-1.490)$ & 0.167 & & \\
\hline Never or occasionally & 9 & $4(44.4 \%)$ & & & & \\
\hline \multicolumn{7}{|c|}{ Hand washing habit after defecation } \\
\hline Often or always & 191 & $40(20.9 \%)$ & $0.642(0.057-7.222)$ & 0.719 & & \\
\hline Never or occasionally & 22 & $12(54.5 \%)$ & & & & \\
\hline \multicolumn{7}{|l|}{ Water source for drinking } \\
\hline Pipe water & 199 & $47(23.6 \%)$ & $0.433(0.131-1.428)$ & 0.388 & & \\
\hline River/stream/lake & 14 & $5(35.7 \%)$ & & & & \\
\hline \multicolumn{7}{|l|}{ Swimming habit } \\
\hline Often or always & 37 & $16(43.2 \%)$ & $0.617(0.285-1.338)$ & 0.222 & & \\
\hline Never or occasionally & 175 & $36(20.6 \%)$ & & & & \\
\hline \multicolumn{7}{|l|}{ Shoe wearing habit } \\
\hline Often/always & 155 & 31 (20.0\%) & $2.27(1.168-4.413)$ & 0.016 & $1.225(0.238-6.297)$ & 0.808 \\
\hline Never/occasionally & 58 & $21(36.2 \%)$ & & & & \\
\hline
\end{tabular}


Table 4 Factors associated with intestinal helminth co-infection among TB patients attending selected health institutions of Arba Minch town and Arba Minch zuria district from January to August, 2016 (Continued)

\begin{tabular}{|c|c|c|c|c|}
\hline Raise ca & & & & \\
\hline Yes & 63 & $14(22.2 \%)$ & $1.187(0.590-2.388)$ & 0.630 \\
\hline No & 150 & $38(25.3 \%)$ & & \\
\hline Raise $p$ & & & & \\
\hline Yes & 73 & $13(17.8 \%)$ & $1.782(0.881-3.604)$ & 0.108 \\
\hline No & 140 & 39 (27.9\%) & & \\
\hline Use nig & & & & \\
\hline Yes & 32 & 7 (21.9\%) & $1.182(0.479-2.916)$ & 0.717 \\
\hline No & 181 & 45 (24.9\%) & & \\
\hline
\end{tabular}

recruited in the present study that drugs and associated health services might play a role for lower prevalence of under nutrition. Patients with $\mathrm{BMI}<18.5$ were 3.511 (95\% CI $=1.646-7.489)$ times at higher risk of acquiring helminth co-infection. Findings from China go in line with our results $[11,23]$. This is expected as helminths cause under-nutrition $[27,28]$. We had got no significant association between anti-TB treatment and its duration with helminth co-infection similarly with studies from China [11, 23]. This is unexpected and needs further large scale study accompanying effects of anti-TB drugs on host immune profile. As a limitation, immunological parameters and worm load were not assessed so that their role on TB pathogenesis could be justified.

\section{Conclusion}

The co-infection rate of intestinal parasitic infection among PTB patients was $26.3 \%$ and that of intestinal helminths only was $24.4 \%$ in Arba Minch. A. lumbricoides was the most prevalent helminth with infection rate of $11.3 \%$. Rural residence, frequent habit of eating raw vegetables/fruits without washing or peeling off and malnutrition $(\mathrm{BMI}<18.5)$ were associated factors with intestinal helminth co-infection among PTB patients. We recommend to health care providers to screen and treat TB patients for intestinal helminthiasis. Health education about transmission and prevention of intestinal parasites should also be part of TB case management to ensure good TB prognosis.

Table 5 Clinical data associated with intestinal helminth co-infection among TB patients attending health institutions of Arba Minch town and Arba Minch zuria district from January to August, 2016

\begin{tabular}{|c|c|c|c|c|c|c|}
\hline Variable & Number examined & Rate of helminth infection (\%) & Crude OR (95\% Cl) & $P$ value & Adjusted OR & $P$ value \\
\hline \multicolumn{7}{|l|}{$\overline{\mathrm{BMI}}$} \\
\hline$<18.5$ & 71 & $25(35.2 \%)$ & $2.315(1.217-4.401)$ & 0.010 & $3.511(1.646-7.489)$ & 0.001 \\
\hline$\geq 18.5$ & 142 & $27(19.0 \%)$ & & & & \\
\hline \multicolumn{7}{|c|}{ Started anti-TB treatment } \\
\hline Yes & 200 & $50(25.0 \%)$ & $1.833(0.393-8.554)$ & 0.441 & & \\
\hline No & 13 & $2(15.4 \%)$ & & & & \\
\hline \multicolumn{7}{|c|}{ Duration of anti-TB treatment } \\
\hline 1-2 months & 45 & $10(22.2 \%)$ & $1.230(0.535-2.828)$ & 0.885 & & \\
\hline 2-4 months & 55 & $14(25.5 \%)$ & $1.029(0.484-2.186)$ & & & \\
\hline \multicolumn{7}{|l|}{$>4$ months } \\
\hline \multicolumn{7}{|c|}{ Course of treatment } \\
\hline First & 190 & $46(24.2 \%)$ & $0.479(0.130-1.772)$ & 0.270 & & \\
\hline Re-treatment & 10 & $4(40.0 \%)$ & & & & \\
\hline \multicolumn{7}{|l|}{ HIV status } \\
\hline Positive & 20 & $3(15.0 \%)$ & $1.929(0.546-6.871)$ & 0.110 & & \\
\hline Negative & 189 & $48(25.4 \%)$ & & & & \\
\hline
\end{tabular}




\section{Abbreviations}

AOR: Adjusted odds ratio; BMl: Body-mass index; Cl: Confidence interval; HIV: Human immunodeficiency virus; IL: Interleukin; PTB: Pulmonary tuberculosis; STH: Soil transmitted helminths; TB: Tuberculosis; Th: T helper; WHO: World Health Organization

\section{Acknowledgements}

We thank health professionals working in TB clinics and laboratories of Arba Minch Hospital and selected health centers for their contribution during data collection; and Arba Minch University for funding the research. We are grateful to ethical review boards of Arba Minch University for giving ethical clearance. Our regards also go to the study subjects for giving consent to participate in the study.

\section{Funding}

Fund for data collection and analysis was obtained from Arba Minch University. No fund was obtained for designing of the study, result interpretation and manuscript writing.

\section{Availability of data and materials}

The original data for this study is available from the corresponding author.

\section{Authors' contributions}

GA conceived and designed the project. GA and MM performed the experiment, analyzed the data and wrote the manuscript. Both authors read and approved the final manuscript.

\section{Competing interests}

The authors declare that they have no competing interests.

\section{Consent for publication}

Not applicable.

\section{Ethics approval and consent to participate}

Ethical approval for the research was granted by review boards of Arba Minch University with a project code of Gov/AMH/5-2/CMHS/MLS/01/08. Official permission letter was also obtained from Arba Minch Hospital and health offices of Arba Minch town and Arba Minch zuria district. Informed verbal consent was obtained from all participating study subjects. All laboratory results were communicated to study participants promptly so that positive patients could be treated in the TB clinics.

\section{Received: 30 October 2016 Accepted: 6 January 2017}

Published online: 13 January 2017

\section{References}

1. WHO. Global Tuberculosis report. Geneva-27: WHO; 2016

2. Kassu A, Mengstu G, Ayele B, Diro E, Mekonnen F, Ketema D, et al. HIV and intestinal parasites in ad ult TB patients in ateaching hospital in Nor thwest Ethiopia. Trop Doct. 2007;37:224-6.

3. Elias D, Mengstu G, Akuffo H, Britton S. Are intestinal helminths risk factors for developing active tuberculosis? Trop Med Int Health. 2006;11:551-8.

4. Abate E, Belayneh M, Gelaw A, Idh J, Getachew A, Alemu S, et al. The impact of asymptomatic helminth co-infection in patients with newly diagnosed tuberculosis in North-West Ethiopia. PLoS One. 2012;7(8):e42901. doi:10.1371/journal.pone.0042901.

5. Chan J, Kaufmann SHE. Immune mechanism of protection in Tuberculosis: pathogenesis, protection and control. Am Soc Microbio Washington DC. 1994;389-415.

6. Bentwich Z, Kalinkovich A, Weisman Z. Immune activation is a dominant factor in the pathogenesis of African AIDS. Immunol Today. 1995:16:187-91.

7. Belkaid $Y$, Rouse BT. Natural regulatory T cells in infectious disease. Nat Immunol. 2005;6:353-60

8. Pessanha AP, Martins RA, Mattos-Guaraldi AL, Vianna A, Moreira LO. Arginase-I expression in granulomas of tuberculosis patients. New Jersey: Blackwell Publishing Ltd; 2012.

9. Gong $J \mathrm{H}$, Zhang $\mathrm{M}$, Modlin RL, Linsley $\mathrm{PL}$, Lyer $\mathrm{P}$, Lin $\mathrm{Y}$, et al. Interleukin-10 downregulates Mycobacterium tuberculosis-induced Th1 responses and CTLA-4 expression. Infect Immun. 1996;64:913-8.
10. Borkow G, Weisman Z, Leng Q, Stein M, Kalinkovich A, Wolday D, et al. Helminths, human immunodeficiency virus and tuberculosis. Scand J Infect Dis. 2001;33:568-71.

11. Li XX, Chen JX, Wang LX, Tian LG, Zhang YP, Dong SP, et al. Prevalence and risk factors of intestinal protozoan and helminthinfections among pulmonary tuberculosis patients without HIVinfection in a rural county in P. R. China. Acta Trop. 2015;149:19-26.

12. Resende Co T, Hirsich CS, Toossi Z, Dietze R, Ribeiro-Rodrigues R. Intestinal helminth co-infection has a negative impact on both anti- Mycobacterium tuberculosis immunity and clinical response to tuberculosis therapy. Clin Exp Immunol. 2007:147(1):45-52.

13. Alemayehu M, Birhan W, Belyhun Y, Sahle M, Tessema B. Prevalence of smear positive tuberculosis, intestinal parasites and their co-infection among tuberculosis suspects in Gondar University Hospital and Gondar Poly Clinic, North West Ethiopia. J Microb Biochem Technol. 2014;6(4):179-84.

14. Ayalew A. Knowledge and practice of malaria prevention methods among residents of Arba Minch Town and Arba Minch Zuria District, Southern Ethiopia. Ethiop J Health Sci. 2010;20(3):185-93.

15. Gibson RS. A laboratory manual. New York: Oxford University Press; 1993.

16. WHO. Management of severe malnutrition: a manual for physicians and other senior health workers. Available: <http://www.who.int/nutrition/>publications/ severemalnutrition/en/manage_severe_malnutrition_eng.pdf. Accessed 14 Aug 2016.

17. Cheesbrough M. Parasitological tests. District laboratory practices in tropical countries. Cambridge: Cambridge University Press; 2000.

18. Ebba Abate, Meseret Belayneh, Jonna Idh, Ermias Diro, Daniel Elias, Sven Britton, et al. Asymptomatic helminth infection in active tuberculosis is associated with increased regulatory and Th-2 responses and a lower sputum smear positivity. PLoS Negl Trop Dis. 2015; http://dx.doi.org/10. 1371/journal.pntd.0003994.

19. Wakabi W. Extension workers drive Ethiopia's primary health care. Lancet. 2008;372:880. doi:10.1016/s0140-6736(1008)61381-61381.

20. Mama M, Alemu G. Prevalence and factors associated with intestinal parasitic infections among food handlers of Southern Ethiopia: cross sectional study. BMC Public Health. 2016;16:105. doi:10.1186/s12889-12016-12790-x.

21. Deribe K, Meribo K, Gebre T, Hailu A, Ali A, Aseffa A, et al. The burden of neglected tropical diseases in Ethiopia, and opportunities for integrated control and elimination. Parasit \& Vectors. 2012;5(1):240

22. Andereck JW, Kipp AM, Ondiek M, Vermund SH. Helminth prevalence among adults in rural Kenya: a stool survey for soil-transmitted helminths and schistosomiasis in Nyanza province. Trans R Soc Trop Med Hyg. 2014:108(12):804-9.

23. Li XX, Chen JX, Wang LX, Tian LG, Zhang YP, Dong SP, et al. Intestinal parasite co-infection among pulmonary tuberculosis cases without human immunodeficiency virus infection in a rural county in China. Am J Trop Med Hyg. 2014;90:106-13.

24. WHO. Nutritional care and support for patients with Tuberculosis. Geneva: WHO; 2013

25. Dodor EA. Evaluation of nutritional status of new tuberculosis patients at the Effia-Nkwanta Regional Hospital. Ghana Med J. 2008;42(1):22-8.

26. Bhargava A, Chatterjee $M$, Jain $Y$, Chatterjee B, Kataria A, Bhargava M, et al Nutritional status of adult patients with pulmonary tuberculosis in rural central India and its association with mortality. PLoS One. 2013;8(10):e77979. doi:10.1371/journal.pone.0077979.

27. Hall A, Hewitt G, Tuffrey $V$, de Silva N. A review and meta-analysis of the impact of intestinal worms on child growth and nutrition. Matern Child Nutr. 2008:4(1):118-236.

28. Albonico M, Allen H, Chitsulo L, Engels D, Gabrielli A-F, Savioli L. Controlling soil-transmitted helminthiasis in pre-school-age children through preventive chemotherapy. PLoS Negl Trop Dis. 2008;2(3):e126 doi:10.1371/journal.pntd.0000126. 